\section{Category}

Synthesis of

Materials and

Unnatural Products

\section{Key words}

divergent synthesis

biselenophenes
Y.-C. PAO, Y.-L. CHEN, Y.-T. CHEN, S.-W. CHENG, Y.-Y. LAI, W.-C. HUANG, Y.-J. CHENG* (NATIONAL CHIAO TUNG UNIVERSITY, HSIN-CHU, TAIWAN)

Synthesis and Molecular Properties of Tricyclic Biselenophene-Based Derivatives with Nitrogen, Silicon, Germanium, Vinylidene, and Ethylene Bridges

Org. Lett. 2014, 16, 5724-5727.

\title{
Divergent Synthesis of Tricyclic Biselenophene-Based Derivatives
}

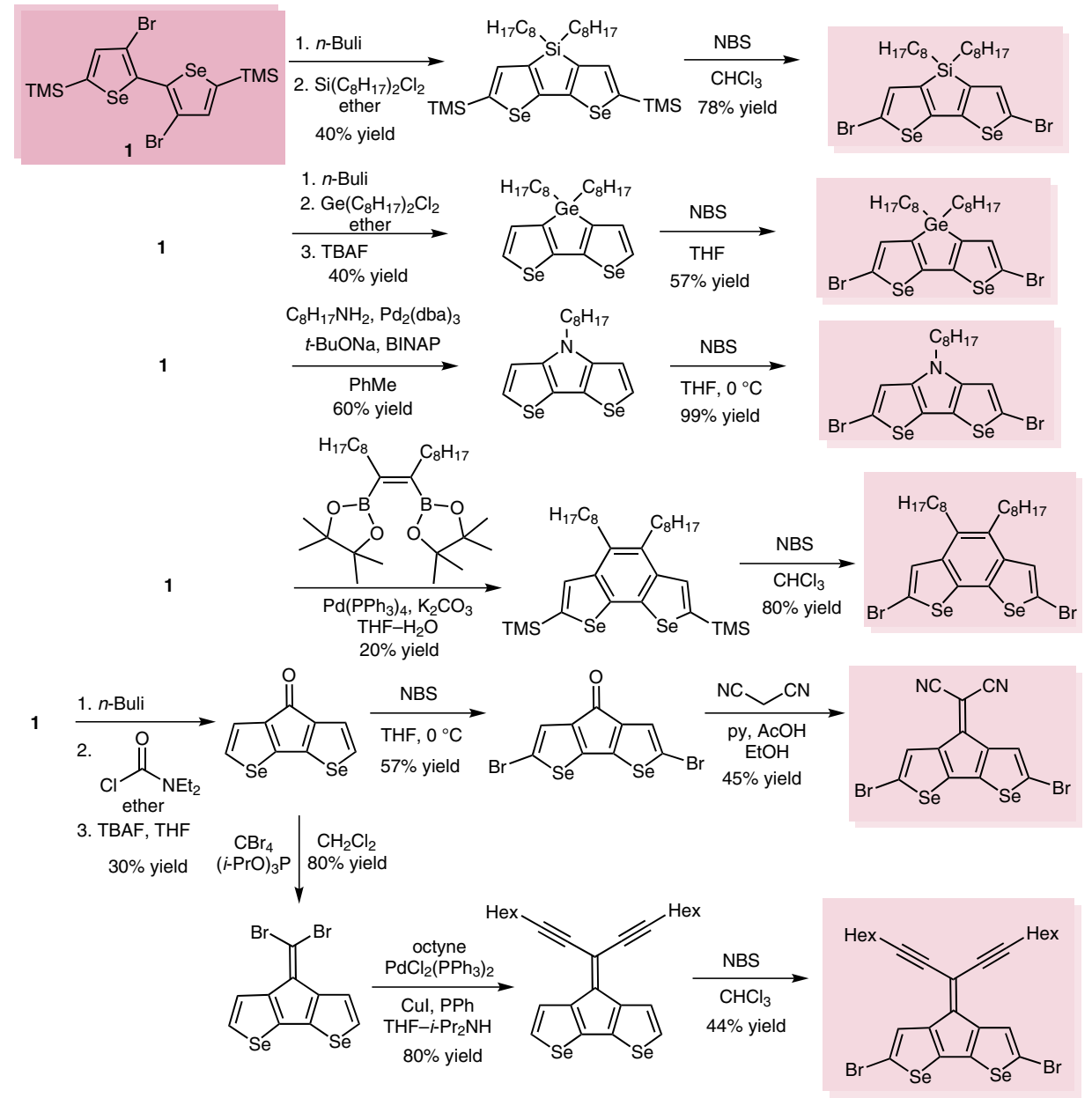

Significance: While tricyclic bithiophene-based materials have been extensively studied as an important class of organic semiconductors, the corresponding biselenophene-based analogues have not been reported. Cheng and co-workers demonstrate for the first time that biselenophene $\mathbf{1}$ can be utilized as starting material for the synthesis of a new class of both $\mathrm{sp}^{3}$-bridged and $\mathrm{sp}^{2}$ bridged tricyclic biselenophene-based materials.
Comment: The six brominated molecules highlighted above can be used as monomers to create a new class of $\mathrm{p}$ - or $\mathrm{n}$-type polymers for exploring biselenophene-based materials in various optoelectronic applications, such as organic field-effect transistors and polymer solar cells. 